\title{
The Enlightenment of Tao Xingzhi's Thought of "Integration of teaching, learning and doing" to Higher Education Teaching in China - From the Perspective of Body
}

\author{
Zhai Mingge \\ School of Education, Tianjin University \\ Tianjin 300354, China
}

\begin{abstract}
The combination of teaching, learning and doing proposed by Mr. Tao Xingzhi emphasizes the improvement of teaching methods from the perspective of making full use of body, which is of great significance for improving the teaching level of higher education in our country at present. In the teaching process of higher education, both teachers and students should be taken as the core, through the development and application of their respective bodies, the time of traditional teaching can be extended, and the space can be extended, and the teaching process can become a harmonious process of teaching and learning between teachers and students.
\end{abstract}

Keywords-Combination of teaching,learning and doing; Higher education teaching; Body; Enlightenment

\section{INTRODUCTION}

On the afternoon of 31 August 2016, Minister of Education Chen Bao-sheng in China pointed out in the State Council's report on the work of higher Education Reform and Development at the 22nd meeting of the standing Committee of the Twelfth National people's Congress: China's higher education has made great progress, but the problems such as big but not strong, lack of vigor and so on are still outstanding, and there is still a big gap with the development needs of the country and the expectations of the people. In the next step, we will make great efforts to adjust the structure of higher education, improve the teaching level and innovative ability of colleges and universities, strengthen the guarantee of higher education conditions, develop higher quality higher education, and speed up the construction of a powerful country in higher education. This fully affirms the important role of teaching activities in improving the quality of higher education in China. This paper tries to probe into the enlightenment of Tao Xingzhi's thought on teaching, learning and doing to higher education teaching in our country from the aspect of body.
II. FROM THE ASPECT OF BODY TO ANALYSE THE MEANING OF "INTEGRATION OF TEACHING, LEARNING AND DOING"

\section{A. The main contents of the integration of teaching,learning and doing}

"The theory of the integration of teaching, learning and doing includes three aspects: first, how to do is how to learn, how to learn is how to teach; second, for thing is doing, for oneself is learning, for others is teaching; and third, education is not just teaching people, nor teaching people to study, but teaching people to do things. Whatever it is, "doing" becomes the center of learning, that is, the center of teaching."[1] The first aspect of the theory of the integration of teaching, learning and doing emphasizes the starting point of students' learning and teachers' teaching. Students learn from doing and teachers teach according to students' learning. Tao Xingzhi's educational thought of combining teaching, learning and doing redefines that the starting point of education is life itself, which is a real and changing reality, not just the general knowledge of certainty in textbooks. The second aspect clarifies that the integration of teaching, learning and doing is a complete process, not a simple split of "teaching", "learning", "doing". The third point is that education is not just teaching people, but teaching people to do something, so that people learn to grow in doing things.

Mr. Tao Xingzhi stressed that by becoming a centre of learning, it became a center of teaching. By doing, the whole teaching process is connected, not the separation of the teacher's teaching knowledge from the students' acceptance of knowledge, and the students' learning activities are not only the individual's isolated learning, but also the cooperative learning with others. In the process of learning in cooperation with others, if it can have a positive impact on others, it also produces the effect of teaching. How to do so, Mr. Tao Xingzhi also made his own explanation and answer. "'doing' is to take action in physical, also to make change in mind. Therefore, 'doing' contains three characteristics: (1) action; (2) thought; (3) the generation of new values. [1]"doing, the simplest meaning is to act,. How to act, to follow blindly, to do without purpose is not the real thing." To do is to have a direction, a need for a 
method, and an individual's unique perception, which means the whole process of cognition, experience, new ideas, value from doing that can bring positive influence to others.

\section{B. From the aspect of body to analyse "the integration of teaching, learning and doing"}

In the Collection of Tao Xingzhi, there is also an expression for the unity of teaching, learning and doing. "We can't admit that physical and mental are separated by the definition of 'doing' in terms of labor. The meaning of automation has the function of force and mind at the same time, that is, the cooperation of body and mind. "[2] This actually shows that the essence of doing is the harmonious operation of the body and the mind of the individual, but in the current education system, the student's body as an individual is often ignored.

The unity of teaching, learning and doing advocated by Tao Xingzhi emphasizes "doing" as the core, and through the full use of both teachers' and students' bodies, the separated teaching activities are turned into a harmonious process of teaching and learning between teachers and students. Teachers and students think and solve problems through the body of each other to experience. In this process, teachers and students are living individuals, and based on their own experience, they would have real feeling and experience, and there is a real exchange between them. Instead of "the individual mind becomes the other's racecourse, the world that is accused of filling up, their voices are drowned by a unified grand voice, and gradually lose their ability and confidence to speak.'[3]

\section{THE ANALYSIS OF PROBLEM AND ITS REASON OF HIGHER EDUCATION TEACHING}

\section{A. The present situation and problems of higher education teaching}

1) The main aim of Teaching: to cultivate people's talents

With the development of economy, the social service function of the university is gradually strengthened, the students' learning purpose is also biased towards utilitarianism. And influenced by the social environment, the starting point of what they want to do is mostly utility. If education only starts from the cultivation of students' professional knowledge and skills, and pays too much attention to talent rather than the cultivation of people, it is very likely that the people who have been cultivated will become "tools" for social construction and lack fresh vitality, unique and complete personality.

\section{2) Main teaching content-based on deterministic} knowledge

The learning of deterministic knowledge makes students often in a passive state. In such an educational environment, people often find a stable state of life, study and work. People trained in such an educational environment tend to look for a stable state of life, study and work, and it is not easy to take the initiative in the changing environment and actively seek solutions to break the bad state. It is also easy to compromise because of the environment. Especially under the circumstances of rapid change and development of the social environment, the people trained by deterministic knowledge would lack flexibility and creativity, and the lasting power of life.

\section{3) The way of Teaching-One-way knowledge teaching}

In the system of education in China, teachers and students are almost always a state of teaching and being taught, and it is a kind of top-down direct indoctrination. Teaching behavior is a simple displacement of knowledge. Teachers take knowledge out of textbooks and pass it on to students. The simple imparting of knowledge makes students only need simple memory of their brains, and there is almost no profound understanding and thinking of knowledge. It is not easy to guide them in the field of further exploration and innovation.

\section{B. Analysis of the causes of Teaching problems in higher Education}

From the very beginning, teaching in China has paid too much attention to teaching, and the part of student learning is simply understood as a passive acceptance process. At the stage of higher education, students have a certain right to choose courses in the curriculum, but the whole process of education is continued, students are still regarded as the object of education. The most prominent manifestation of this is that students' bodies are not respected. In the whole process of education and teaching, students' physical activities and direct experience of their own bodies are ignored.

The body for someone as an individual is the unity of body and mind, sensibility and reason, consciousness and unconsciousness; for the outside world, it is the fulcrum of communication and communication with the body of the other, and the existence of the contact relationship between the subject and the gaze [4]. However, in the teaching of higher education, educators still pay too much attention to the improvement of individual intelligence and the accumulation of professional knowledge, but do not see that the development of individual integrity needs the harmonious unity of body and mind, especially with the full development of the body. "On the road to knowledge without the body, the student's head can only get bigger and bigger, the body can only become smaller and smaller. This kind of physical 'absence' education makes teaching and learning actually become the mechanical movement of knowledge transmission. [5]"

From the point of view of teaching purpose, higher education often neglects the desire and request of students' personal development from the angle of cultivating social talents. From the teaching content, students usually study the deterministic knowledge. Gradually they cultivate the stability of inertia and thinking, the lack of active thinking and doubt of the quality and ability. From the perspective of teaching methods, students are generally passive, lack of communication and communication in the teaching process. The whole education process emphasizes too much the teaching purpose and standard outside the educatee, which makes the student passively accept, but does not pay attention to each student's individuality characteristic. As a result, it is difficult for students to have personal experience and feelings, and lack the spirit of questioning and exploration.

Therefore, in the modern education concept, only let "pay attention to students' body and the influence of it" replace 
"only focus on students' grades and Intellectual growth" ,can stimulate the original motive force of modern education, so that the quality of life of the educated can be really improved, the modern education can return to the world of human life, let the human society, history, nature in the most primitive sense of harmony, burst out in the real world of sentimental light [6].

\section{THE ENLIGHTENMENT OF THE COMBINATION OF TEACHING,LEARNING AND DOING TO THE TEACHING OF HIGHER EDUCATION FROM THE PERSPECTIVE OF BODY}

\section{A. Break the limitation of time and space and extend teaching process}

Traditional teaching is only the transmission of deterministic knowledge, and this communication process is often unidirectional, which is basically manifested in the teaching of teachers and the acceptance of students. The student's body is hardly taken seriously and is completely restricted. Mr. Tao Xingzhi had suggested that, in the present situation, six liberations should be carried out, and that the fundamental freedom of study should be returned to the students: first, to free his mind so that he could think; second, to free his hands so that he could do it; and third, to free his eyes so that he can see; fourth, to liberate his mouth so that he can talk; fifth, to liberate his space so that he can go to the great world of nature to obtain more abundant learning; sixth, to liberate his time, not fill up his homework sheet, and do not force him to rush into the examination, do not unite with his parents in his homework, and give him some free time to digest what he has learned, and to learn what he is eager to learn, do something he is happy to do [7]. This fully demonstrates that the physical body is not only as the existence carrier of the individual, but also the development and the effective utilization of the various senses of the body are beneficial to the complete and comprehensive development of human beings.

Mr. Tao Xingzhi's six liberations are the result of a lack of education and neglect of students' physical activity. The certainty of teaching content makes students have no space to explore and discover, the passive acceptance of teaching method makes students have no opportunity to express and communicate. The limited teaching space makes students get used to the constant sense of security in the fixed space gradually. Their bodies become lazy, and gradually they lack the courage and curiosity to explore outward. Without the stimulation of new things in the senses and the experience of changes in different circumstances, it is difficult for individuals to have new experiences and feelings.

Mr. Tao Xingzhi said that the unity of teaching, learning and doing is through the use of the body, including teachers' and students', the use of the body, both through real and vivid individual communication to make teaching activities effective and vivid. Students through the body of their own experience, teachers through the body to teach the knowledge activated. Teaching activities are not only a simple process of knowledge transfer, but also a process of exploring and discussing knowledge between teachers and students, in which they can communicate and debate equally. The whole teaching activity is not only limited to the one-way transmission behavior of deterministic knowledge above the classroom, but also breaks through the narrow space of classroom and the limited time of classroom study through the doing and performance of the body of teachers and students. It has become the common process of seeking truth between teachers and students, and the traditional teaching activities are also infinitely extended.

\section{B. Teachers should learn together and grow with their students}

The teaching method emphasized by Tao Xingzhi is that teachers should work together with students in teaching, learning and doing, especially should learn according to the methods of students learning. When students are asked to do things, the teaching staff do what they have learned. The students are required to follow the rules, and the teaching staff bow to each other. We are convinced that this method of colearning, co-education, and co-cultivation is true education [8].

Teachers should change their ideas, not just as disseminators of knowledge. Teachers should also make full use of their own bodies in the process of learning knowledge. They should not only pay attention to the source of teaching content from textbooks, but also to the environment and concrete application of the corresponding theories. Otherwise, the knowledge that teachers impart can only be theories, which can not convey their true feelings to students without corresponding experiences.

In addition, teachers should also try to know the character of the student group, pay attention to updating their teaching methods. As teachers, they have been in the same teaching position and field for a long time, and may face the same knowledge content, but they should never simply repeat themselves when teaching. They need to realize that the students they are facing are different, their ideas, the ways of communicating and accepting things are constantly changing. So as teachers must constantly update the way of imparting knowledge, and resonate with students so that they can better understand and absorb knowledge.

\section{Students should promote the harmonious development of body and mind in the process of doing}

For the students receiving higher education, they must realize the importance of using their body, and fully exercise their body in the university to have a good physique, and obtain their own unique cognition and feeling through the full use of the body to develop a complete personality.

In the way of learning, we should strengthen cooperative learning, discuss and solve problems with students and teachers in a team. In the process of cooperation, a group of people in the team work together on a problem or topic. Individuals must do it with their hands, take part in it, cooperate with others, and find their place in the team. How a team goal match their inner expectations, and how they express their ideas to others in the process, is something individuals can't exercise in a single learning process. This is what Mr. Tao Xingzhi called "phase teaching and learning". It connects and influences the whole teaching process through the participation and interaction of everyone. In the content of learning, in addition to the study of deterministic knowledge in traditional teaching, one should also increase the accumulation of personal practical experience 
to have roots on which one can rely and establish their own cognitive system. In college, learning as an individual should be more active, through physical practice to achieve better development. Do it and practice it in specific situations; use eyes to increase visual experience; use mouth to express thoughts and communicate with others; listen with ears and absorb nutrients to enrich the heart; step forward and go out of school and experience in society.

\section{CONCLUSION}

Teaching activities are the focus of school education, and the improvement of teaching quality depends on the effective development of teaching activities in school education. Mr. Tao Xingzhi's idea of the integrating teaching, learning and doing, emphasizing the core 'doing', is actually emphasizing that both teachers and students make full use of their bodies to influence each other and learn from each other in doing things together. This will break the phenomenon of teaching separation in the teaching activities of higher education in China, which will help to promote the integration of teaching and learning, the growth of teachers and students, and the improvement of the teaching quality of higher education in our country.

\section{REFERENCES}

[1] Tao Xingzhi. Tao Xingzhi complete set 2 Teaching textbook [M]. Changsha: Hunan Education Press, 1985: 557652.(In Chinese)

[2] Tao Xingzhi. Tao Xingzhi [M]. Nanjing: Jiangsu people's Publishing House. 1981: 231. (In Chinese)

[3] Yan Xurei. Body: perspective of Perspective Education [J]. Educational Theory and practice 2007, (4). (In Chinese)

[4] Qiu Kunshu, Yan Yinjun. Body and body Education in Education [J]. The monthly Journal of Education and academic Studies is 11: 14-16. (In Chinese)

[5] Feng Heguo. From the relationship between body and Education to explore the turn of the body of Contemporary Education [J]. Shanghai Educational and Scientific Research Co., Ltd. (4). (In Chinese)

[6] Zhang Zailin, Feng Heguo. On the Transformation of Modern Educational idea from the body Phenomenology of Melo Ponty [J]. Educational theory and practice 2015 04: 3-7. (In Chinese)

[7] Tao Xingzhi. Discussion on the basic problems in Future Education [M]. Chengdu: Sichuan Education Press. 2005: 342. (In Chinese)

[8] Tao Xingzhi. Tao Xingzhi complete works 8 students and teachers live together [M]. Chengdu: Sichuan Education Press. 1991: 97. (In Chinese) 